\title{
SGLT2 inhibitor reduces urinary protein excretion even in the advanced diabetic kidney disease patients
}

\author{
Kazunobu Yoshimura, Kaito Waki, Ryutaro Iijima and Hiroyuki Terawaki* \\ Department of Internal Medicine, Nephrology, Teikyo University Chiba Medical Center, Chiba, Japan
}

Sir,

It is widely recognized that massive albuminuria / proteinuria in diabetic nephropathy (DN) is related to rapid progress of kidney dysfunction [1]. Therefore, clinical approach to reduce urinary protein excretion, such as usage of renin-angiotensin system inhibitor and restriction of protein intake, is widely performed as clinical practice.

Recently, new class antidiabetic drug - SGLT2 inhibitor - appeared in clinical use. One of the distinct characteristics of SGLT2 inhibitor is its suppressive potential for urinary albumin / protein. The suppression of urinary albumin / protein is closely related to remission of renal tubular damage which is characterized by increased L-FABP, $\beta 2$-microglobulin and NAG [2]. Such beneficial effect among DN has already been confirmed in CKD stage from G1 to G3a [3]. However, the effect of SGLT2 inhibitor among DN patients with more advanced kidney damage - especially with CKD stage G4 and G5 - is not confirmed.

We prescribed SGLT2 inhibitor to eight DN patients with various CKD stages (number of patients; $G 5=2, G 4=2, G 3=2, G 2=1$ and $G 1=1$ ) in addition to current medication for two months. Patients' profile is shown in Table 1. Prescription except for XORI was not changed at all.

As a result, significant suppression of urinary protein $(\mathrm{g} / \mathrm{gCre}$, UPCR) level was observed (Table 2). There was no difference between before and after SGLT2 inhibitor administration regarding systolic blood pressure, estimated glomerular filtration rate, serum albumin, serum uria nitrogen, serum uric acid, hemoglobin Alc and hemoglobin (Table 2).

When patients were stratified into two groups according to CKD stage (G4+G5 and G1+G2+G3), the suppression of UPCR after SGLT2 inhibitor addition was observed in both patients' groups. Interacrtion $\mathrm{P}$ between two groups was greater than $0.2(\mathrm{P}=0.1608)$, suggesting that the decrease of UPCR in the patients with severely impaired kidney function might be superior than that in patients with mildly impaired kidney function (Figure 1).

Several reports support the possibility of tubule-centric concept which claims that albuminuria / proteinuria among DN is caused not only by glomerulopathy but also mainly by tubulopathy [4]. Previously, we compared the urine of DN patients with that of non-diabetic CKD patients, and we found that chemokine which represents tubular damage (CXCL5) was increased only in DN patients in correlation with urinary albumin level [5]. From the viewpoint of tubule-centric concept, our finding suggests that administration of SGLT inhibitor could lessen tubule-intestinal damage of DN patients even in the far-advanced stage. SGLT2 belongs to solute carrier family (SLC5A2) which action as a transporter simply depends on substrate concentration. High concentration of glucose in blood (and thus, in glomerular filtrate) could "force-feeds" proximal tubules over-absorption of glucose, just like farmer force-feeds ducks and geese to make Foie gras. If that is the case, SGLT2 administration might rescue tubules and interstitial tissue from Foie gras situation.

Our present report is merely before-after observation and thus it is insufficient to make final decision that UP lowering effect of SGLT2 inhibitor is significant among far-advanced stage of DN patients in the clinical setting. We believe, however, further study regarding this hypothesis is warranted.

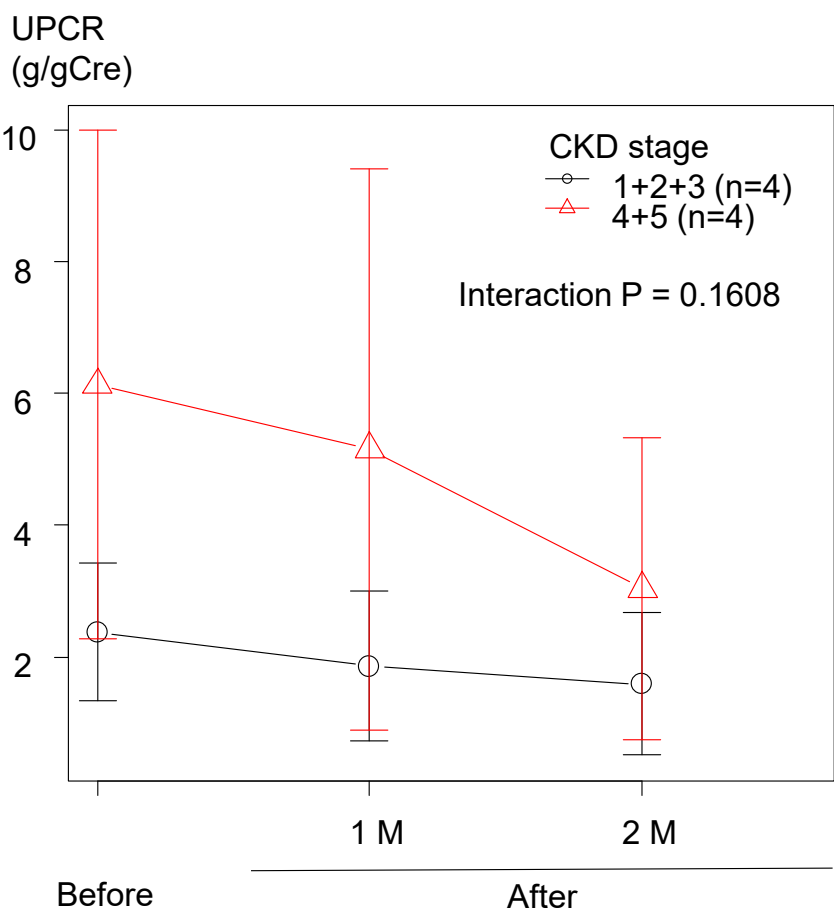

Figure 1. The relationship between change of UPCR and kidney function The decrease of UPCR is observed even in the patients with severely impaired kidney function (CKD stage G4 and G5).

${ }^{\star}$ Correspondence to: Hiroyuki Terawaki, Professor, Department of Nephrology, Teikyo University Chiba Medical Center, 3246-3, Anesaki, Ichihara City, Chiba, 299-0111, Japan, Tel: +81-436-62-1211; Fax: +81-436-562-7340; E-mail: terawaki@med.teikyo-u.ac.jp

Received: October 26, 2018; Accepted: October 29, 2018; Published: November 04,2018 
Table 1. Patients' profile

\begin{tabular}{|c|c|c|c|c|c|c|c|c|}
\hline Case & Age & Gender & $\begin{array}{l}\text { Height } \\
\mathrm{cm}\end{array}$ & $\begin{array}{l}\text { Weight } \\
\quad k g\end{array}$ & $\begin{array}{c}\mathrm{BMI} \\
\mathrm{kg} / \mathrm{m}^{2}\end{array}$ & $\begin{array}{l}\text { Estimated GFR } \\
\mathrm{mL} / \mathrm{min} / 1.73 \mathrm{~m}^{2}\end{array}$ & $\begin{array}{c}\text { Urunary protein } \\
\text { g/gCre }\end{array}$ & $\begin{array}{c}\text { Added SGLT2 inhibitor } \\
\text { daily dose }\end{array}$ \\
\hline \multicolumn{9}{|c|}{ Stage $4+5$} \\
\hline 1 & 45 & $\mathrm{~F}$ & 153.8 & 75.9 & 32.087 & 6.6 & 11.12 & Luseogliflozin $2.5 \mathrm{mg}$ \\
\hline 2 & 74 & M & 153.8 & 52.6 & 22.2368 & 10.6 & 5.36 & Luseogliflozin $2.5 \mathrm{mg}$ \\
\hline 3 & 56 & M & 176.0 & 124.0 & 40.031 & 15.8 & 1.75 & Luseogliflozin $2.5 \mathrm{mg}$ \\
\hline 4 & 87 & $\mathrm{~F}$ & 150.6 & 45.1 & 19.885 & 29.4 & 6.27 & Luseogliflozin $2.5 \mathrm{mg}$ \\
\hline \multicolumn{9}{|c|}{ Stage $1+2+3$} \\
\hline 5 & 75 & $\mathrm{M}$ & 156.7 & 57.5 & 23.4169 & 47.8 & 1.03 & Empagliflozin $10 \mathrm{mg}$ \\
\hline 6 & 60 & $\mathrm{~F}$ & 158.1 & 48.7 & 19.4834 & 49.1 & 2.05 & Canagliflozin $100 \mathrm{mg}$ \\
\hline 7 & 64 & M & 165.0 & 72.0 & 26.4463 & 61.8 & 3.28 & Dapagliflozin $5 \mathrm{mg}$ \\
\hline 8 & 44 & $\mathrm{~F}$ & 160.5 & 122.0 & 47.3598 & 95.0 & 3.14 & Luseogliflozin $2.5 \mathrm{mg}$ \\
\hline
\end{tabular}

Table 2. The change of parameters including urinary protein-creatinine ratio (UPCR) before and after SGLT2 inhibitor administration

\begin{tabular}{|c|c|c|c|c|}
\hline & \multirow{2}{*}{ Before } & \multicolumn{2}{|c|}{ After } & \multirow{2}{*}{$\begin{array}{c}\text { P-value } \\
\text { (One factor-ANOVA })\end{array}$} \\
\hline & & $1 \mathrm{M}$ & $2 \mathrm{M}$ & \\
\hline Systolic blood pressure $\mathrm{mmHg}$ & $138 \pm 10$ & $137 \pm 18$ & $130 \pm 10$ & 0.3772 \\
\hline Estimated GFR $\mathrm{mL} / \mathrm{min} / 1.73 \mathrm{~m}^{2}$ & $39.5 \pm 30.3$ & $36.9 \pm 27.7$ & $37.5 \pm 30.1$ & 0.1812 \\
\hline Serum albumin $g / d L$ & $3.8 \pm 0.5$ & $3.8 \pm 0.5$ & $3.8 \pm 0.5$ & 0.9402 \\
\hline Serum urea nitrogen $m g / d L$ & $34.9 \pm 29.0$ & $37.0 \pm 29.8$ & $37.0 \pm 32.9$ & 0.5563 \\
\hline Serum uric acid $m g / d L$ & $6.7 \pm 1.4$ & $6.3 \pm 2.0$ & $6.9 \pm 2.4$ & 0.2113 \\
\hline Hemoglobin A1c \% & $6.7 \pm 0.6$ & $6.6 \pm 0.6$ & $6.6 \pm 0.5$ & 0.8676 \\
\hline Hemoglobin $g / d L$ & $12.4 \pm 2.4$ & $12.3 \pm 2.9$ & $12.4 \pm 2.8$ & 0.8825 \\
\hline UPCR $g / g C r e$ & $4.25 \pm 3.29$ & $3.51 \pm 3.38$ & $2.31 \pm 1.83$ & $0.0150 *$ \\
\hline
\end{tabular}

3. Petrykiv S, Sjöström CD, Greasley PJ, Xu J, Persson F, et al. (2017) Differential effects of dapagliflozin on cardiovascular risk factors at varying degrees of renal function. Clin J Am Soc Nephrol 12: 751-759. [Crossref]

1. Abe M, Okada K, Maruyama N, Takashima H, Oikawa O, et al. (2016) Comparison of clinical trajectories before initiation of renal Replacement Therapy between diabetic nephropathy and nephrosclerosis on the KDIGO Guidelines Heat Map. J Diabetes Res 2016: 5374746

2. Takashima H, Yoshida Y, Nagura C, Furukawa T, Tei R, et al. (2018) Renoprotective effects of canagliflozin, a sodium glucose cotransporter 2 inhibitor, in type 2 diabetes patients with chronic kidney disease: A randomized open-label prospective trial. Diab Vasc Dis Res 15: 469-472. [Crossref]

4. Comper WD, Hilliard LM, Nikolic-Paterson DJ, Russo LM (2008) Diseasedependent mechanisms of albuminuria. Am J Physiol Renal Physiol 295: F15891600. [Crossref]

5. Higurashi M, Ohya Y, Joh K, Muraguchi M, Nishimura M, et al. (2009) Increased urinary levels of CXCL5, CXCL8 and CXCL9 in patients with Type 2 diabetic nephropathy. J Diabetes Complications 23: 178-184. [Crossref]

Copyright: (C2018 Yoshimura K. This is an open-access article distributed under the terms of the Creative Commons Attribution License, which permits unrestricted use, distribution, and reproduction in any medium, provided the original author and source are credited. 